\title{
THE ORDNANCE SURVEY
}

"I AM told," said Robert Louis Stevenson, "that there are people who do not care for maps, and I find it hard to believe." As if in substantiation of his belief, the Ordnance Survey during 1963-64 printed no less than 4 million maps and issued 3 million for sale, the highest total ever in one period of twelve months. Of these, the incomparably popular One Inch to One Mile Series accounted for almost half, the Quarter Inch Series for another quarter. In all, there are now just less than 100,000 different present-day sheets on all scales, and most of the small-scale series (one inch and smaller) are complete. The bulk of the outstanding programme comprises the $1: 1,250$ and $1: 2,500$ plan series, each of which is being produced at an annual rate of several thousand sheets, though so vast is their coverage that 150,000 are still needed. Moreover, the extent and rapidity of new building, motorway construction and other developments over the changing face of Britain necessitate a perpetual programme of revision, according to a careful scheme of priorities. This new material is sometimes required so urgently by public users that the Ordnance Survey makes it available through its Advanco Revision Information Service.

Apart from this steady long-term progress, 1963-4 saw the appearance of a number of individual sheets of special interest. These include the beautiful map of Hadrian's Wall, plotted on a modern topographical basemap on a two inches to a mile scale, and a composite sheet of the Isles of Scilly on the $1: 25,000$ scale. A twosheet edition of a Route Planning Map, in six colours, on a scale of 10 miles to an inch, has proved to be of such value to road-users, with its wide range of supplementary information, that it has already been reprinted three times since its first appearance in January 1964. New editions of the attractive Tourist Maps of the Lake District, the North York Moors and the Peak District have appeared, joined by a new recently published Cairngorms sheet which reflects the growing popularity of this mountain group as a ski-ing and climbing area. Preliminary work has been carried out on a proposed tourist map of the Cambridge district.

All this has been accomplished by a total personnel of only 4,500 , whose headquarters in the near future will be the fine building under construction in Southampton. The Ordnance Survey first came to that town in 1841, following a fire in the Tower of London which had destroyed its premises. A century later, though Southampton still remained the centre of the drawing and printing activities of the Ordnance Survey, the administrative headquarters were transferred to Chessington in Surrey. When the new building is completed, the disadvantages of scattered and inadequate accommodation will be overcome, and the Ordnance Survey will have returned home.

The accomplishment of so much with such a relatively small personnel has been practicable only by the constant introduction of technological improvements: the extension of aerial photography (though badly hindered in 1963-64 by long periods of poor flying weather), the acquisition of new stereo-plotting machines to make use of the photographs, the use of electromagnetic distancemeasuring equipment (by this means precise travers es were measured from Dover to Cape Wrath and from Land's End to East Anglia), the trials of an automatic stereocomparator using punched cards, the installation of automatic reading planimeters for measuring areas on the $1: 2,500$ plans, and new economical methods of multicoloured printing.

One of the most interesting achievements has involved the completion of a new geodetic connexion across the English Channel, in conjunction with the Institut Géographique Nationale. Both angular and electromagnetic distance measurements were made from points near the coast of the Isle of Wight, Portland Bill and the Cotentin peninsula, with the collaboration of the Royal Corps of Signals and a Hydrographic Survey Ship in mid-Channel. Similar enterprises in recent years have linked the geodetic systems of Scotland and Scandinavia, using radar and a high-flying aircraft, and have tied Rockall into the triangulation network.

The Ordnance Survey's annual report for 1963-64*, with a few pages of text, numerous statistical tables, and some 'progress maps', summarizes in prosaic form a wealth of fascinating cartographical activity. A gross expenditure of almost $£ 5$ million was partially offset by receipts of nearly $£ 1 \frac{1}{4}$ million; the balance has indeed been spent to good account. In the words of the Director General, this work is ". . . not only of the highest importance but also of abundant and abiding interest to those who do it".

F. J. Monkhouse * The Ordnance Survey Annual Report, 1963-64. Pp. $11+12$ appendixes
+9 plates. (London: H.M.S.O., 1964.) 68. net.

\section{EARTH SCIENCES IN THE U.S.S.R.}

\footnotetext{
HE following account is based on articles in the journal Priroda. A general review of the whole field of present-day research is provided by D. I. Shcherbakov (the editor of Priroda) and A. L. Yanshin (1, 44; 1963), who discuss geochronology, biostratigraphy, palæomagnetism, tectonics, tectonic maps, spores and algae of Precambrian age, ore deposits and methods of survey and prospecting. The last subjects are also discussed by M. F. Grin $(7,2$; 1954), who describes exploration in search of petroleum, natural gas, coal, phosphorites and iron ores.

Geological cycles and tectonics are discussed by N. F. Balukhovsky $(2,54 ; 1963)$, E. D. Sulidi-Kondratiev and V. V. Kozlov $(1,102 ; 1964)$, G. P. Tamrasyan $(1,107$; $1964)$ and D. A. Frank-Kamentsky $(1,110 ; 1964)$. A. I. Rybin $(7,87 ; 1964)$ discusses the causes of the deep-seated gravitational tectogenesis and outlines a hypothesis which would link-up deep-seated movements of the Earth's crust with the Earth's contraction and the phenomenon of isostasy.
}

Geochemistry, a branch of science highly cultivated in the Union, is represented by the articles of A. A. Drobkov $(8,45 ; 1963)$, who discusses chemical elements present in the living matter; V. V. Kovalsky $(3,44 ; 1964)$ discusses geochemical ecology in living matter, while A. I. Perel'man $(5,8 ; 1964)$ proposes a geochemical classification of chemical elements based on their abundance, distribution and migration capacity in the outer geospheres, introducing a new term "coefficient of hydrous migration". Finally, L. S. Tarasov $(8,3 ; 1963)$ most ably presents the hypothesis of the formation of geospheres as proposed by A. P. Vinogradov and his collaborators. According to this hypothesis the original Earth in its composition was similar to the composition of chondrite meteorites, and in the course of time, under the action of localized radiogenic heat, a process analogous to that of 'zone melting' in metals separated the volatile-enriched portions from the refractory components. Laboratory experiments of zone melting of a chondritic meteorite showed the 